\title{
OJED
}

Volume 5, Issue 1 (2020), pp. 136-140

International Journal of

Multidisciplinary Perspectives in Higher Education

ISSN: 2474-2546 Print/ ISSN: 2474-2554 Online

https://ojed.org/jimphe

\section{Doctoral Advising in COVID-19: Opportunity for Change}

\author{
Tania Reis \\ Gannon University, Pennsylvania, USA \\ Marilyn Grady \\ University of Nebraska-Lincoln, Nebraska, USA
}

\begin{abstract}
Doctoral advising is a complex process. In times of uncertainty, doctoral programs offer a unique opportunity for advisors to embrace a new pedagogical and intersectional role.
\end{abstract}

Keywords: doctoral advising, higher education, university, student success

Doctoral education has many components. Common elements of a doctoral program include course work, comprehensive exams, a dissertation proposal and a dissertation defense. Although there is variation between disciplines, and among university program designs, most U.S. doctoral programs set a completion requirement between five to seven years of continuous study. Success of a student in an individual doctoral program is often linked to overlapping factors connected to discipline of study, faculty relationships, institutional design, academic readiness, family responsibilities, and financial stability. In the end, numerous elements combine to support or derail terminal degree completion (Gardner \& Gopaul, 2012; West, Gokalp, Peña, Fisher \& Gupton, 2011).

The doctoral journey is challenging within multiple personal constructs. Pervious research has focused on doctoral student attrition as understood through social processes and academic isolation (Golde, 2000; Baker, Pifer \& Flemion, 2013). The social development of a doctoral student connected to faculty, peers and the institution can lead to decreased 
attrition and higher completion rates (Gardner, 2008, 2009a, 2009b, 2010). However, what happens when an international pandemic erupts, and changes the process of social interaction?

Doctoral education is broadly defined, and encompasses multiple disciplines and acronyms to designate a terminal degree. Thus, to frame the context of this paper, we position ourselves (Creswell \& Poth, 2018) within the paradigm. We are faculty at U.S. universities where we advise doctoral students in Ed.D. and Ph.D. programs. The programs in which we teach incorporate distance and asynchronous courses with hybrid and face-to-face opportunities. Our programs enroll mid to late-career adult learners who work within PK-12 schools, higher education, and business organizations.

According to Danby and Lee (2012), doctoral program design includes pedagogy, and an interactive element is embedded in doctoral student training. Teaching and learning are not separate constructs but are implicitly connected through program delivery. Learning is co-created, not only in class content, but through social connection. More so, social connection bridges to program design, and includes intentional interaction between the student and doctoral advisor (Barnes \& Austin, 2008; Grady, 2012; Harding-Dekam, et al., 2012)

A relational connection between a doctoral advisor and advisee mitigates program attrition, and supports degree completion. Doctoral advisors socialize students to discipline and program designs (Barnes, 2010). Doctoral advisors make implicit elements of the curriculum explicit, and convey not only subject knowledge, but ways to integrate course content with individual research or experience (Harding-Dekam, et al., 2012). An effective advisor can smooth obstacles, and support students in maintaining an effective timeline. Regular meetings and goal setting between the student and advisor are important to creating an effective advisor/advisee relationship (Barnes et al, 2012; Shore, 2014).

Advisors provide career and intellectual guidance, but often the relationship merges into psychosocial dimensions (Gammel \& RusteinRiley, 2016; Lunsford, 2012). Due to the tenure of the relationship, and the "all in" experience of doctoral education, many advisors know their students personally. Names of partners, children, pets and parents are commonly shared between an advisee and their advisor. As doctoral advisors, we have received emails, phone calls, pictures, and texts about life celebrations and losses, financial pressures, home relocations, child graduations, and grandchildren being born. Given the scope in age of doctoral students, any life event is bound to happen. For us, relationship building is part of the doctoral pedagogy, and requires us to acknowledge how a student's life shapes and forms their doctoral experience.

COVID 19 offered an opportunity to broaden the doctoral advisee/advisor relationship, and test the boundaries of understanding. In late February 2020, U.S. colleges and universities reacted to rapidly 
changing conditions related to the spread of the disease. As emails circulated regarding potential cancellation of large group events, universities struggled to create a plan that met the needs of divergent student populations. By late March, the majority of U.S. educational institutions, schools, businesses, stores and restaurants were closed to face-to-face interaction. Universities quickly pivoted to distance learning for all students. Life changed for everyone, and doctoral advising as pedagogy changed, as well.

We started to receive panicked emails from students that described multiple areas of stress shaped within the details of their lives. Students were concerned with completion dates, meeting deadlines, and planning for proposals and defenses as they attended to homeschooling children, elderly parents, fear of illness, fear of job loss, loss of income, and isolation from peers. Students who expected to have an office or library to complete their academic work were now writing on nightstands in bedrooms. In short, there were no rules to protect a student from the next arrow that might fire.

However, COVID 19 offered opportunities to expand interpersonal approaches to advising. Previously, advisor/advisee meetings happened in offices or coffee shops, but now we were meeting students in their homes via Zoom. Zoom gave glimpses into an advisee's personal work space, and captured visuals of children being fed, pets getting walked, knocks on doors, and multiple noise-producing concentration-breaking interruptions, including garbage trucks. Is it important to an advisee's relationship that the advisor knows garbage day is Thursday? Not specifically; but, according to Shore (2014), effective advising understands how life connects to academic ambitions. For the first time, as doctoral advisors, we were more fully in the life of our student versus socializing them into the life of our program.

More so, as Zoom calls froze, and technology failed, we were reminded that wi-fi is indeed, not free. Scheduling calls was complicated for some students that shared computers with family members. Other students lived in homes with more bodies than rooms, and adapted by taking phone calls outside. Connecting during COVID was an important reminder that technology, like many things, is vital but unequal.

Answers to inequality are complicated and elusive; embedded in daily life. Inequalities are also capitalized within the context of social living (Bourdieu, 1986). COVID created a unique situation where advisors balanced program requirements and student realities, and in the end, created personalized avenues for student success. Each doctoral student had a different set of problems that were magnified by loss: loss of money, loss of work, loss of time, loss of peers, loss of productivity.

Even now, as the pandemic defines a new normal within higher education, it is paramount that doctoral advisors remember the lessons learned in the early days of COVID. If we, as doctoral advisors did not know it, we learned it: things that were not equal may not be solved but 
perhaps made better through equitable advising. As doctoral advisors, we are called to meet the student within the definition of themselves, not ourselves. In this way, doctoral advisors can begin to close the margins of inequality in doctoral education.

The implications of COVID are ongoing, and the final effect on U.S. higher education remains unknown. Yet, even in times of uncertainty, doctoral programs offer a unique opportunity for advisors to fully embrace a pedagogy of design (Danby \& Lee, 2012). Just as the pandemic shapes and forms daily operations in grocery stores and restaurants, and reworks personal interactions; the advisor/advisee relationship must embrace an intersectional role. Doctoral advising requires being in the "now" not in the "when," and integrating the realities of life into the relationship. Orientating life experiences into learning transforms both the advisee and advisor, and creates a more diverse and supportive advising practice.

\section{References}

Baker, V.L., Pifer, M. J., \& Flemion, B. (2013). Process challenges and learning-based interactions in Stage 2 of doctoral education: Implications from two-applied social science fields. The Journal of Higher Education, 84(4), 449-477.

Barnes, B. \& Austin, A. E. (2009). The role of doctoral advisors: A look at advising from the advisor's perspective. Innovative Higher advising: a comparison of students' experiences across disciplines. Journal of Further and Higher Education, 36(3), 309-331. https://doi.org/10.1080/0309877X.2011.614933

Education, 33, 297-315. https://doi.org/10.007/s10755-008-9084-x Barnes, B., Williams, E. A., \& Stassen, M.L.A. (2012). Dissecting doctoral Barnes, B.J. (2010). The nature of exemplary doctoral advisors'expectations and the ways they may influence doctoral persistence. Journal of College Student Retention, 11(3), 323-343.

Bourdieu, P. (1986). The forms of capital. In J. Richardson (Ed.), Handbook of theory and research for the sociology of education (pp. 241-258). Greewood.

Creswell, J.W. \& Poth, C. N. (2018). Qualitative inquiry\& research design: Choosing among five approaches $\left(4^{\text {th }}\right.$ ed.) Sage.

Danby, S. \& Lee, A. (2012). Framing doctoral pedagogy as design and action. In A. Lee \& S. Danby (Eds.), Reshaping doctoral education: International approaches and pedagogies (pp. 3-11). Routledge.

Gammel, J.A. \& Rutstein-Riley, A. (2016). A relational approach to mentoring women doctoral students. New Directions for Teaching and Learning, 147, 27-35.

Gardner, S. K. (2008). "What's too much and what's too little?": The process of becoming an independent researcher in doctoral education. The Journal of Higher Education, 79(3), 326-350. 
Gardner, S.K. (2009). Student and faculty attributions of attrition in high and low-completing doctoral programs in the United States. Higher Education, 58(1), 97-112.

Gardner, S.K. (2009). The development of doctoral students: Phases of challenge and support. ASHE Higher Education Report, 34(6), 1-14.

Gardner, S.K. (2010) Contrasting the socialization experiences of doctoral students in high and low completing departments: A qualitative analysis of disciplinary contexts at one institution. The Journal of Higher Education, 81(1), 61-81.

Gardner, S.K., \& Gopaul, B. (2012). The part-time doctoral student experience. International Journal of Doctoral Studies, 7, 63-76.

Golde, C. M. (2000). Should I stay or should I go? Student descriptions of the doctoral attrition process. The Review of Higher Education, 23(2), 199-227.

Grady, M.L. (2012). Doctoral students in a distance program: Advising and degree completion strategies. Journal of Academic Administration in Higher Education, 12(2), 49-52.

Harding-DeKam, J.L., Hamilton, B., \& Loyd, S. (2012). The hidden curriculum of doctoral advising. NACDA Journal, 32(2), 5-16.

Lunsford, L. (2012) Doctoral Advising or Mentoring? Effects on Student Outcomes, Mentoring \& Tutoring: Partnership in Learning, 20(2), 251-270, DOI:10.1080/13611267.2012.678974

Shore, B. M. (2014). The graduate advisors handbook: a student centered approach. The University of Chicago press.

West, I.J., Gokalp, G., Peña, E.V., Fischer, L., \& Gupton, J. (2011). Exploring effective support practices for doctoral students' degree completion. College Student Journal, 45(2), 310-323. 